\title{
Types of Sphenoid Sinus Pneumatization among Nepalese Population.
}

\author{
Pankaj Raj Nepal' ${ }^{1}$, Karuna Tamrakar Karki ${ }^{1}$, Jagat Narayan Rajbanshi ${ }^{1}$
}

${ }^{1}$ Department of Neurosurgery, B and C Medical College Teaching Hospital and Research Center, Birtamode, Jhapa, Nepal

\section{Correspondence:}

Dr. Pankaj Raj Nepal, FCPS, Deputy Medical Director and Head of Department Department of Neurosurgery, B and C Medical College Teaching Hospital and Research Center Birtamode, Jhapa, Nepal.

Email: pankajrajnepal@gmail.com

\begin{abstract}
Background: The sphenoid sinus is a very important route during the surgical procedure for the lesions inside and around the sella tercica. With the aim to evaluate the anatomical variations of these sphenoid sinuses in the Nepalese population, this study was performed. Methods and Materials: This is a CrossSectional analytical study with a non-probability consecutive sampling. Patients of all age groups and all gender who underwent a CT scan of head for any reason were collected, excluding the patients whose sella and / or sphenoid sinus was distorted or fractured for various reasons. A recon image of all the CT scans was made, then were classified base on the sphenoid sinus pneumatization and clival extension of the sphenoid sinus. This was done on the midsagittal image of the CT scan of the head in the bone window. Age was presented as mean and standard deviation (SD), and stratification in groups. Gender, types of sphenoid sinus pneumatization, and clival extension were presented in frequencies and percentages. An association of age and gender with sphenoid sinus pneumatization and clival extension were evaluated using Fischer's Exact test in SPSS 20. Result: The total number of cases enrolled in the study was 58 with a mean age of 41.62 (SD $22.46)$ years. The most common type of sphenoid pneumatization was a complete sellar type (52\%). Similarly, sub-dorsal clival extension (71\%) was more common in this study sample followed by other types. There was a significant association of different age categories with the type of sphenoid pneumatization. The conchal type of the sphenoid pneumatization was exclusively seen only in children. Similarly, gender also showed statistically significant association with the sphenoid pneumatization, where males were associated with more complete type and females with more presellar and incomplete type. Conclusion:The prevalence of complete sellar pneumatization and sub-dorsal type of clival extension were the most common findings in the Nepalese population. Conchal type of sphenoid pneumatization is the predominant findings in childhood. More extensive sphenoid pneumatization and clival extension were the significant findings among the male population.
\end{abstract}

Key words: Pneumatization, Sphenoid Sinus anatomy, Transsphenoidal surgery, Variation of sphenoid sinus.

$\mathrm{T}$ The sphenoid sinus is a very important route during the surgical procedure for the lesions inside and around sella tercica. ${ }^{1-3}$ This sphenoid sinus seems to have various anatomical variations and thus making some of the surgical steps requiring more 14

Date submitted: 16/ 07/2020

Date accepted: 02/09/2020 bone drilling like in conchal type, and some requiring more delicate dissection like the incomplete sellar type., ${ }^{4,5}$ With the aim to evaluate the anatomical variations of these sphenoid sinuses in the Nepalese population, this study was performed.

egneuro, Volume 02, Issue 03, 2020 


\section{Methods and Materials:}

Study Design: Cross-Sectional analytical study

Sampling Technique: Non-probability consecutive sampling

Study duration: 3 months

Site of study: B and C Medical College Teaching Hospital and Research Center, Birtamode, Jhapa, Nepal.

Inclusion Criteria: patients of all age group and all gender who underwent CT scan of head for any reasons

Exclusion Criteria: CT scan of the patients whose sella and / or sphenoid sinus was distorted or fractured for various reasons.

All the patients whose CT scan of the head was done were enrolled in the study. A recon image of all the CT scans was made then was classified base on the sphenoid sinus pneumatization (Figure 1) and clival extension (Figure 2) of the sphenoid sinus.

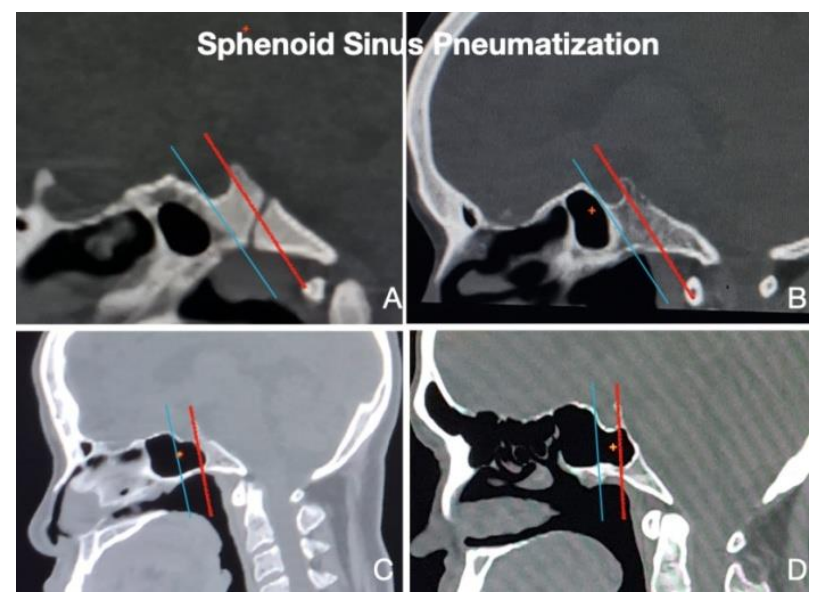

Figure 1: Various types of sphenoid sinus pneumatization. A= Conchal Type: Pneumatizaton more than $10 \mathrm{~mm}$ away from the anterior wall of sella. $B=$ Presellar: Pneumatization just adjacent to the anterior wall of the sella. $C=$ Incomplete sellar: Pneumatization extended below the sella but had not crossed the margin of the posterior wall of sella. D: Complete sellar: Pneumatization extended beyond the posterior margin of the sella. Blue line: the anterior wall of sella, Red line: the posterior wall of sella.

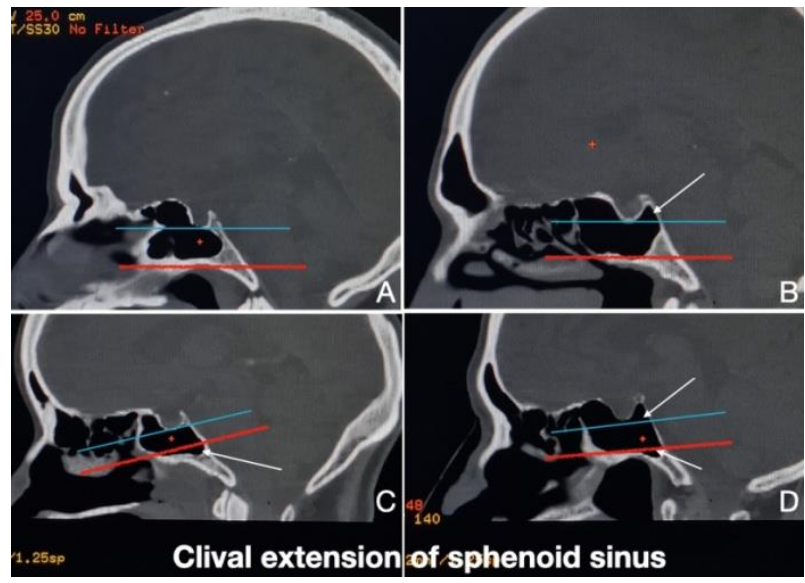

Figure 2: Various types of clival extension: $A=$ Subdorsal: Pneumatization not crossing the limits of the sellar floor and the Vidian canal. $B=$ Dorsal: Pneumatization extending superiorly into the dorsum sella. $\mathrm{C}=$ Occipital: Pneumatization extending inferior beyond the limits of the Vidian canal. $D=$ Combined (Dorsal + Occipital) Blue line: the floor of the sella, red line: limits of Vidian canal, arrowheads: pointing the extension of the pneumatization.

This was done on the midsagittal image of the CT scan of the head in the bone window. The classification was based on the previously published article by Hiremath SB. ${ }^{6}$ Age, gender, and the types of sphenoid sinus pneumatization and clival extension were entered in a preformed proforma. Age was presented as mean and standard deviation (SD), and stratification in groups. Gender, types of sphenoid sinus pneumatization, and clival extension were presented in frequencies and percentages. An association of age and gender with sphenoid sinus pneumatization and clival extension were evaluated using Fischer's Exact test in SPSS 20.

\section{Results:}

The total number of cases enrolled in the study was 58 with a mean age of 41.62 (SD 22.46) years. Age ranged from 4 to 84 years was enrolled in this study (Figure 3). 


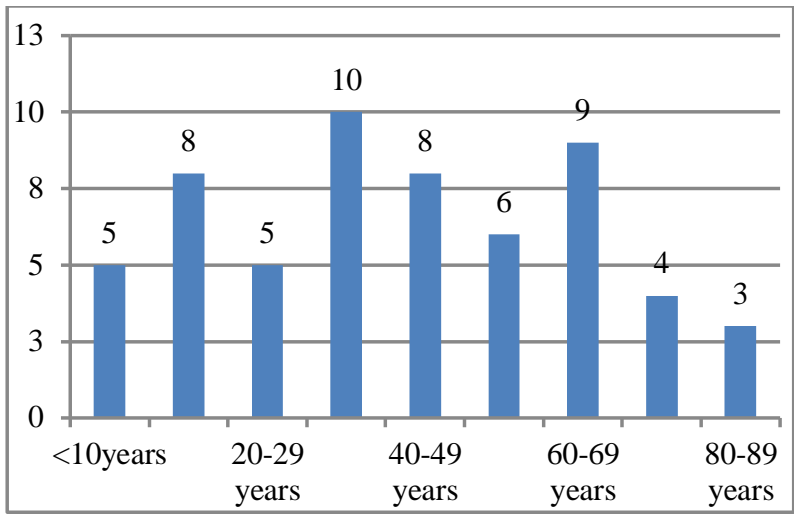

Figure 3: Age distribution of the various age categories

The majority of them were male gender (Figure 4).

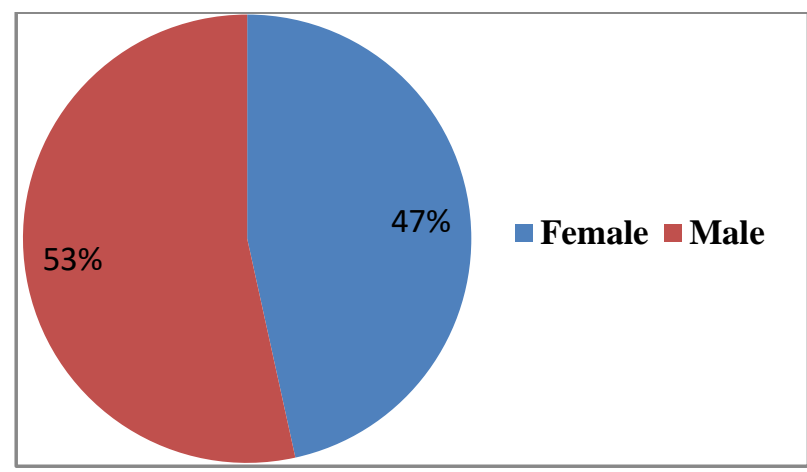

Figure 4: Gender distribution

The most common type of sphenoid pneumatization was a complete sellar type (52\%) followed by incomplete sellar (22\%), presellar (16\%), and conceal type (10\%) (Figure 5).

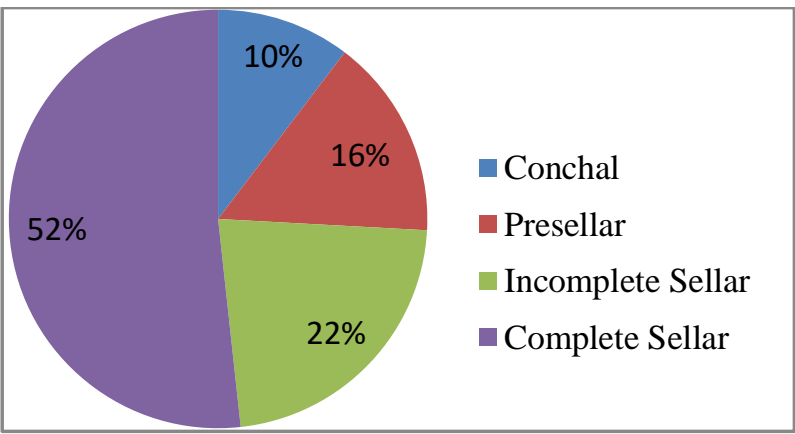

Figure 5: Types of Sphenoid Pneumatization
Similarly, sub-dorsal clival extension (71\%) was more common in this study sample followed by other types (Figure 6).

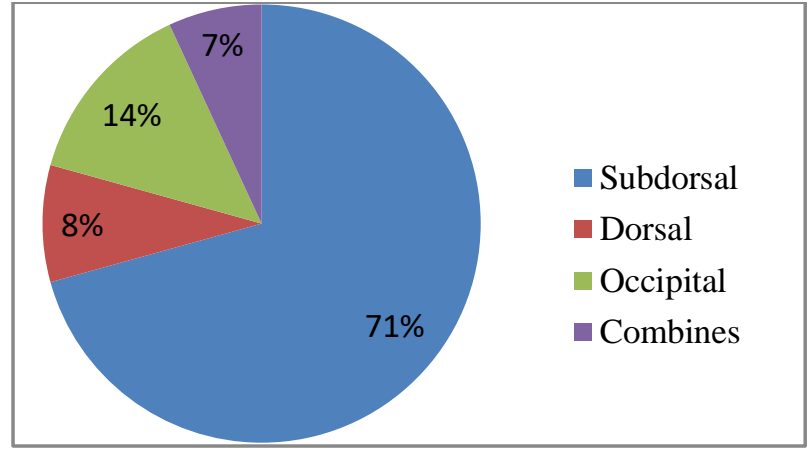

Figure6: Types of clival extension

There was a significant association of different age categories with the type of sphenoid pneumatization (Table 1).

Table 1: Association of Sphenoid Pneumatization

Sphenoid Pneumatization

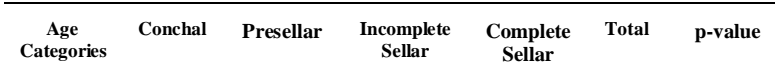

\begin{tabular}{|c|c|c|c|c|c|c|}
\hline $\begin{array}{l}<10 \\
\text { years }\end{array}$ & 5 & 0 & 0 & 0 & 5 & $0.006 *$ \\
\hline $\begin{array}{l}10-19 \\
\text { years }\end{array}$ & 1 & 3 & 2 & 2 & 8 & \\
\hline $\begin{array}{l}20-29 \\
\text { years }\end{array}$ & 0 & 1 & 1 & 3 & 5 & \\
\hline $\begin{array}{l}30-39 \\
\text { years }\end{array}$ & 0 & 1 & 3 & 6 & 10 & \\
\hline $\begin{array}{l}40-49 \\
\text { years }\end{array}$ & 0 & 1 & 0 & 7 & 8 & \\
\hline $\begin{array}{l}50-59 \\
\text { years }\end{array}$ & 0 & 0 & 2 & 4 & 6 & \\
\hline $\begin{array}{l}60-69 \\
\text { years }\end{array}$ & 0 & 2 & 2 & 5 & 9 & \\
\hline $\begin{array}{l}70-79 \\
\text { years }\end{array}$ & 0 & 0 & 2 & 2 & 4 & \\
\hline $\begin{array}{l}80-89 \\
\text { years }\end{array}$ & 0 & 1 & 1 & 1 & 3 & \\
\hline \multicolumn{7}{|l|}{ Gender } \\
\hline Female & 2 & 7 & 10 & 8 & 27 & $0.003 *$ \\
\hline Male & 4 & 2 & 3 & 22 & 31 & \\
\hline
\end{tabular}

egneuro, Volume 02, Issue 03, 2020 
The conchal type of the sphenoid pneumatization was exclusively seen only in children and the other bigger sellar types were more common in the elder population. Similarly, gender also showed statistically significant association with the sphenoid pneumatization, where males were associated with more complete type and females with more presellar and incomplete type.

Gender was also significantly associated with the clival extension of the sphenoid sinus. Here, the males were more associated with more clival extensions like dorsal, occipital, and combined (Table 2). However; females were significantly associated with the subdorsal type. Age was not a significantly associated factor with the clival extension of the sphenoid sinus.

Table 2: Association of Clival extension

\begin{tabular}{|c|c|c|c|c|c|c|}
\hline \multicolumn{7}{|c|}{ Clival Extension } \\
\hline $\begin{array}{c}\text { Age } \\
\text { Category }\end{array}$ & Subdorsal & Dorsal & Occipital & Combined & Total & $\begin{array}{c}\text { P. } \\
\text { value }\end{array}$ \\
\hline$<10$ years & 5 & 0 & 0 & 0 & 5 & 0.395 \\
\hline $\begin{array}{l}10-19 \\
\text { years }\end{array}$ & 8 & 0 & 0 & 0 & 8 & \\
\hline $\begin{array}{l}20-29 \\
\text { years }\end{array}$ & 3 & 1 & 1 & 0 & 5 & \\
\hline $\begin{array}{l}30-39 \\
\text { years }\end{array}$ & 6 & 3 & 1 & 0 & 10 & \\
\hline $\begin{array}{l}40-49 \\
\text { years }\end{array}$ & 5 & 0 & 2 & 1 & 8 & \\
\hline $\begin{array}{l}50-59 \\
\text { years }\end{array}$ & 3 & 0 & 2 & 1 & 6 & \\
\hline $\begin{array}{l}60-69 \\
\text { years }\end{array}$ & 6 & 0 & 2 & 1 & 9 & \\
\hline $\begin{array}{l}70-79 \\
\text { years }\end{array}$ & 2 & 1 & 0 & 1 & 4 & \\
\hline $\begin{array}{l}80-89 \\
\text { years }\end{array}$ & 3 & 0 & 0 & 0 & 3 & \\
\hline \multirow{2}{*}{ Gender } & 24 & 0 & 2 & 1 & 27 & $0.023^{*}$ \\
\hline & 17 & 5 & 6 & 3 & 31 & \\
\hline
\end{tabular}

\section{Discussion:}

The sphenoid sinus is usually not formed during birth and the area is filled with bone marrow. ${ }^{7}$ This sinus seems to gradually form during childhood egneuro, Volume 02, Issue 03, 2020 and usually completes at the age of 14 years. The formation of the sphenoid sinus starts at the anterior superior part, which gradually extends towards inferiorly and posterolaterally. The extension of the sphenoid sinus usually doesn't occur after the age of 25 years. ${ }^{8}$ In this study, there was a significant association of age with sphenoid sinus pneumatization. The findings of our study suggested that the conchal type of sphenoid pneumatization is a predominant finding of childhood and there were no cases of concha type of pneumatization after the age of 20 years. This association might be due to the natural process of pneumatization which starts from the anteriorsuperior part in early childhood. ${ }^{7}$ The prevalence of complete sellar sphenoid pneumatization was more beyond the age of 30 years also correlates with the previous study showing cessation of sphenoid pneumatization by the age of 25 years.

The prevalence of complete sellar pneumatization seems to be highest among other types in most of the literature, which ranges between $59-86 \%{ }^{10-13}$ Similarly, in our study, there were $52 \%$ of complete sellar sphenoid pneumatization. This lower prevalence of complete sellar sphenoid pneumatization seems to be due to the inclusion of all ages during sampling. The conchal type of sphenoid pneumatization is reported between $0-3 \%$ in different works of literature, where most of the study was done only for the adult population. ${ }^{6,13}$ In our study, there was $10 \%$ of conchal sphenoid pneumatization, However, all of them were below the age of 20 years, and the prevalence of conchal type pneumatization in adults was $0 \%$ which was consistent with other studies. ${ }^{6}$

Subdorsal sphenoid pneumatization was the most common type of clival extension whose prevalence was $71 \%$ in our study. This finding also seems to be similar to previous studies. ${ }^{6}$ Besides age, there was a significant association of gender with various types of sphenoid pneumatization and clival extension. The findings from this study showed male gender seems to possess more extensive sphenoid pneumatization (complete sellar) and clival extension (Dorsal, Occipital, and Combined type) compared to the female counterpart, who seems to have less developed sphenoid pneumatization (presellar and incomplete sellar) and less extensive clival extension (Subdorsal). 
This gender difference in the extend of sphenoid sinus pneumatization might be one of the reasons for the difference in the resonance of sound between the genders. ${ }^{14,15}$

\section{Conclusion:}

The prevalence of complete sellar pneumatization and sub-dorsal type of clival extension were the most common findings in the Nepalese population. Conchal type of sphenoid pneumatization is the predominant findings in childhood. More extensive sphenoid pneumatization and clival extension were the significant findings among the male population.

\section{References:}

1. Liu JK, Das K, Weiss MH, Laws ER, Couldwell WT. The history and evolution of transsphenoidal surgery. Journal of neurosurgery. 2001 Dec 1;95(6):1083-96.

2. Partington MD, Davis DH, Laws ER, Scheithauer BW. Pituitary adenomas in childhood and adolescence: Results of transsphenoidal surgery. Journal of neurosurgery. 1994 Feb 1;80(2):209-16.

3. Alfieri HJ. Endoscopic transsphenoidal pituitary surgery: various surgical techniques and recommended steps for procedural transition. British Journal of Neurosurgery. 2000 Jan 1;14(5):432-40.

4. Kinnman J. Surgical aspects of the anatomy of the sphenoidal sinuses and the sella turcica. Journal of anatomy. 1977 Dec;124(Pt 3):541.

5. Hamid O, El Fiky L, Hassan O, Kotb A, El Fiky S. Anatomic variations of the sphenoid sinus and their impact on trans-sphenoid pituitary surgery. Skull base. 2008 Jan; 18(1):9.

6. Hiremath SB, Gautam AA, KeerthySheeja GB. Assessment of variations in sphenoid sinus pneumatization in Indian population: A multidetector computed tomography study. The Indian journal of radiology \& imaging. $2018 \mathrm{Jul} ; 28(3): 273$.

7. Scuderi AJ, Harnsberger HR, Boyer RS. Pneumatization of the paranasal sinuses: normal features of importance to the accurate interpretation of CT scans and MR images. AJR. American journal of roentgenology. 1993 May;160(5):1101-4.

8. Carter LC, Pfaffenbach A, Donley M. Hyperaeration of the sphenoid sinus: cause for concern?. Oral Surgery, Oral Medicine, Oral Pathology, Oral Radiology, and Endodontology. 1999 Oct 1;88(4):506-10.

9. Aoki S, Dillon WP, Barkovich AJ, Norman D. Marrow conversion before pneumatization of the sphenoid sinus: assessment with MR imaging. Radiology. 1989 Aug;172(2):373-5.

10. Baskin JZ, Kuriakose MA, Lebowitz RA. The anatomy and physiology of the sphenoid sinus. Operative Techniques in Otolaryngology-Head and Neck Surgery. 2003 Sep 1;14(3):168-72.

11. Bonneville JF, Dietemann JL. Radiology of the sella turcica. Springer Science \& Business Media; 2012 Dec 6.
12. Bruneton JN, Drouillard JP, Sabatier JC, Elie GP, Tavernier JF. Normal Variants of the Sella Turcica: Comparison of Plain Radiographs and Tomograms in 200 Cases. Radiology. 1979 Apr;131(1):99-104.

13. Sevinc O, Is M, Barut C, Erdogan A. Anatomic variations of sphenoid sinus pneumatization in a sample of Turkish population: MRI study. Int. j. morphol. 2014 Dec 1;32(4):1140-3.

14. Havel M, Kornes T, Weitzberg E, Lundberg JO, Sundberg J. Eliminating paranasal sinus resonance and its effects on acoustic properties of the nasal tract. Logopedics Phoniatrics Vocology. 2016 Jan 2;41(1):33-40.

15. Fraederich M, Aboelhasan MF, Knips J, Heiland M, Friedrich RE. Nasal speech associated with hyperaeration of the sphenoid sinus. in vivo. 2015 Mar 1;29(2):281-7. 